Une déclaration d'un comité consultatif (DCC) Comité consultatif de la médicine tropicale et de la médecine des voyages (CCMTMV) ${ }^{\dagger}$

\title{
DÉCLARATION SUR LA FIĖVRE JAUNE À L'INTENTION DES VOYAGEURS
}

\section{Préambule}

Le Comité consultatif de la médecine tropicale et de la médecine des voyages (CCMTMV) fournit à l'Agence de la santé publique du Canada, de façon continue et en temps utile, des conseils de nature médicale, scientifique et de santé publique concernant les maladies tropicales infectieuses et les risques pour la santé associés aux voyages à l'étranger. L'Agence reconnaît que les conseils et les recommandations figurant dans cette déclaration reposent sur la pratique médicale et les connaissances scientifiques les plus à jour, et les diffuse dans le but d'informer les voyageurs ainsi que les professionnels de la santé qui sont appelés à leur prodiguer des soins.

Les personnes qui administrent ou utilisent des médicaments, des vaccins ou d'autres produits devraient bien connaître le contenu des monographies de produit ou des autres normes ou modes d'emploi approuvés. Les recommandations relatives à l'usage des produits et les autres renseignements présentés ici peuvent différer de ceux qui figurent dans la monographie ou toute autre norme ou instruction approuvée et pertinente établie par les fabricants autorisés. Rappelons que l'approbation demandée par les fabricants pour leurs produits, avec démonstration de leur innocuité et de leur efficacité à l'appui, ne s'applique qu'aux utilisations conformes à la monographie ou autre norme ou mode d'emploi approuvé.

Membres : Dr A. McCarthy (Président); Dr A.K. Boggild; Dr J. Brophy; Dr Y. Bui; Dr M. Crockett; Dr C. Greenaway; Dr W. Ghesquiere; Mme A. Henteleff; Dr M. Libman; Dr P.J. Plourde; Dr P. Teitelbaum.

Représentants d'office : Dr P. Charlebois; Dr P. McDonald; Dr S. Schofield; Dr M. Tepper.

Représentants de liaison : Dr G. Brunette; Dr C. Hui.

Membre émérite : Dr C.W.L. Jeanes.

† Le présent document a été préparé par P. Charlebois et approuvé par le CCMTMV. 


\section{Table des matières}

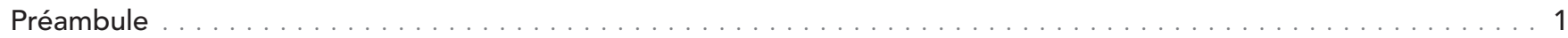

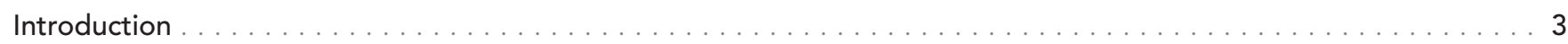

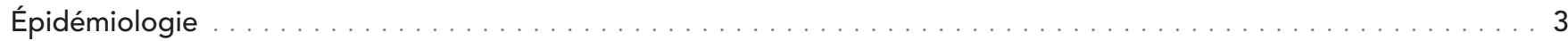

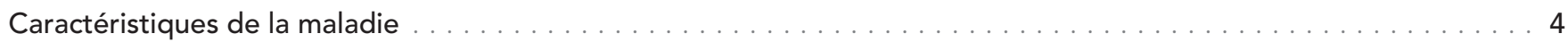

Risque pour les voyageurs . . . . . . . . . . . . . . . . . . . . . . . . . .

Mesures de prévention . . . . . . . . . . . . . . . . . . . . . . . . . . .

Règlement sanitaire international et mesures de prévention de la fièvre jaune . . . . . . . . . . . . 6

Vaccination contre la fièvre jaune au Canada. . . . . . . . . . . . . . . . . . . 6

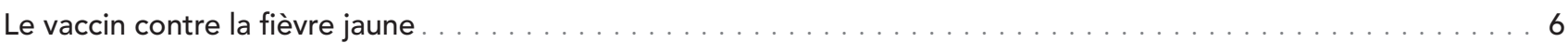

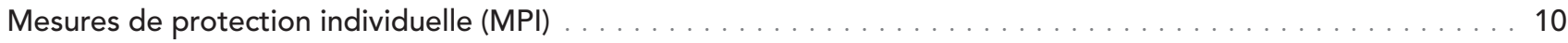

Conséquences possibles si les bons documents ne sont pas présentés . . . . . . . . . . . . . .

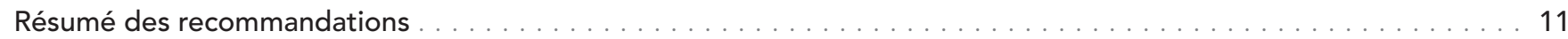

Tableau 1 : Fermeté et qualité des preuves—tableau récapitulatif . . . . . . . . . . . . . . 11

Tableau 2 : Recommandations sur l'administration du vaccin contre la fièvre jaune en fonction du groupe. . . . . . 11

Annexe 1 : Zones à rique de la fièvre jaune . . . . . . . . . . . . . . . . . . . . . . . .

Annexe 1a : Critères de classification des risques pour la fièvre jaune, $2011 \ldots \ldots$

Annexe $1 \mathrm{~b}$ : Pays où il y a un risque de transmission de la fièvre jaune, par continent, $2011 \ldots \ldots$

Annexe 1c : Recommendations concernant la vaccination antiamarile, Afrique, $2010 \ldots \ldots$

Annexe 1d : Recommendations concernant la vaccination antiamarile, Amériques, 2010 . . . . . . . . . . . 14

Annexe 2 : Centres de vaccination contre la fièvre jaune au Canada . . . . . . . . . . . . . . . . 15

Annexe 2a : Exemple de Certificat international de vaccination ou de prophylaxie délivré

par l'Agence de la santé publique du Canada . . . . . . . . . . . . . . . . . . . .

Annexe $2 \mathrm{~b}$ : Exemple de Certificat de contre-indication médicale à la vaccination délivré par l'Agence de la santé publique du Canada . . . . . . . . . . . . . . . . . . . . . .

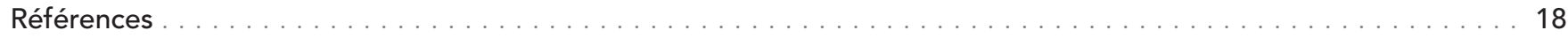




\section{Introduction}

La fièvre jaune est une maladie à transmission vectorielle qui peut être évitée par la vaccination et qui est causée par un virus appartenant à la famille des Flaviviridæ. Dans sa forme la plus grave, cette maladie provoque une fièvre hémorragique dont le taux de mortalité clinique est élevé malgré la prise de mesures de soutien vigoureuses. Le virus de la fièvre jaune est le prototype du genre Flavivirus, qui comprend environ 70 autres virus, dont le virus de la dengue, le virus de l'encéphalite japonaise et le virus du Nil occidental (1-3).

Selon l'Organisation mondiale de la santé (OMS), la maladie frapperait chaque année approximativement 200000 personnes et entraînerait environ 30000 décès. La maladie est actuellement endémique et parfois épidémique en Amérique du Sud et en Afrique (1;4).

\section{Épidémiologie}

La fièvre jaune est endémique et parfois épidémique dans certaines régions de l'Afrique et de l'Amérique du Sud. Bien que des moustiques vecteurs soient présents en Asie, il n'existe aucun cas documenté de transmission du virus sur ce continent. II existe trois cycles de transmission du virus de la fièvre jaune:

1. Le cycle forestier ou selvatique : Dans les forêts tropicales, plusieurs espèces de moustiques (appartenant par exemple aux genres Aedes et Haemagogus) transmettent le virus à une population hôte composée de primates non humains, lesquels transmettent à leur tour le virus à d'autres moustiques. Au fur et à mesure que la transmission du virus se poursuit, les personnes exposées aux moustiques peuvent être infectées. Celles qui vivent et travaillent dans la forêt ou à proximité de celle-ci risquent de contracter la maladie dans le cadre du cycle forestier/ selvatique $(1 ; 3)$;

2. Le cycle urbain : Dans les régions plus urbaines, des moustiques de l'espèce Aedes aegypti agissent comme vecteur principal de la maladie. Les épidémies qui surviennent dans le cadre du cycle urbain sont habituellement dues à I'introduction du virus dans l'environnement par un moustique infecté ou par une
Selon les données historiques, la fièvre jaune est un agent pathogène important. Les premières recherches sur la maladie faisaient pour la plupart suite aux éclosions qui se sont produites durant la construction du canal de Panama et la guerre hispano-américaine. Les premières recherches sur la maladie faisaient pour la plupart suite aux éclosions qui se sont produites durant la construction du canal de Panama et la guerre hispano-américaine. Cependant, des épidémies de fièvre jaune ont sévi en Amérique du Nord jusqu'au début du 20e siècle (5).

La vaccination des populations réceptives a permis de réduire considérablement les taux d'infection chez les populations humaines. Étant donné que le virus de la fièvre jaune est transmis par des moustiques vecteurs, la lutte contre les moustiques et les mesures de protection individuelle contre les piqûres de moustiques font également partie intégrante des mesures de prévention de l'infection par le virus de la fièvre jaune, et sont utilisés conjointement avec la vaccination pour atténuer l'impact de la maladie dans les régions où elle est endémique $(1 ; 6-9)$.

personne porteuse du virus. En raison de la forte densité de la population des régions urbaines, ce cycle de transmission de la fièvre jaune peut se traduire par des épidémies explosives $(1 ; 3)$;

3. Le cycle intermédiaire : Dans les petits villages ruraux où les humains et les singes vivent à proximité les uns des autres, des moustiques semi-domestiques (appartenant au genre Aedes) transmettent le virus de la maladie à des humains et à des primates. En règle générale, ce cycle de transmission donne lieu à des épidémies de petite échelle et ne se produit qu'en Afrique.

Selon les données les plus récemment publiées par l'OMS, 42 cas de fièvre jaune ont été déclarés à l'OMS en 2010. Neuf éclosions de fièvre jaune ont été signalées dans six pays. En 2010, les pays suivants d'Afrique centrale et occidentale ont déclaré en tout 20 cas, mais aucun décès : Cameroun $(n=7)$, République démocratique du Congo $(n=2)$, Guinée $(n=9)$ et Sénégal $(n=2)$. En Amérique du Sud, 22 cas confirmés et 17 décès ont été déclarés en 2010 (Bolivie, $n=2$; Brésil, $n=2$; Pérou, $n=18$ ); le taux de létalité s'élevait à 77,3\% (6;10). On croit que l'Amérique du Sud et I'Afrique présentent des taux d'incidence réels qui sont de 10 à 50 fois plus élevés que ce qu'indiquent les données officiellement enregistrées, et ce, en raison du taux élevé 
de sous-déclaration, des limites en matière de surveillance et de diagnostic ainsi que du nombre de personnes infectées qui présentent peu de symptômes cliniques ou aucun (2).

Entre 1970 et 2010, neuf cas de fièvre jaune ont été diagnostiqués chez des voyageurs internationaux non vaccinés venant des États-Unis et de l'Europe. Quatre d'entre eux ont contracté la maladie en Amérique du Sud (Brésil $=3$, Venezuela $=1$ ) et cinq l'ont contractée en Afrique (Sénégal = 2, Côte d'lvoire = 1, Gambie =1, Afrique occidentale $=1)(7 ; 11-15)$. En 1987, un cas de fièvre jaune a été diagnostiqué chez un voyageur vacciné venant de l'Espagne et ayant effectué un voyage en Afrique occidentale. Jusqu'à présent, aucun cas de fièvre jaune n'a été diagnostiqué chez des voyageurs canadiens de retour au pays (16).

Étant donné que le virus de la fièvre jaune continue de se transmettre au sein d'une population hôte composée de primates non humains (dans le cadre du cycle de transmission forestier), il est impossible de procéder à l'éradication de la maladie. Ce phénomène complique également la surveillance mondiale de la maladie $(2 ; 11)$. Depuis quelques années, on s'inquiète aussi du fait que les changements environnementaux, géographiques et anthropiques pourraient influencer la répartition de la maladie: les changements liés au régime des pluies affectent les populations de moustiques et leurs emplacements; de plus, l'accroissement du rythme de déforestation fait en sorte que l'homme se rapproche des hôtes naturels de la fièvre jaune (c.àd. les primates), ce qui pourrait faire augmenter le nombre d'éclosions de fièvre jaune selvatique et/ou intermédiaire. L'urbanisation accrue pourrait provoquer des épidémies humaines plus concentrées, et l'accroissement du commerce et des voyages internationaux évoque la possibilité théorique d'importation ou d'exportation de la maladie (11;17-19).

\section{Caractéristiques de la maladie}

Les manifestations cliniques de la maladie varient quant à leur gravité, allant de l'absence de symptômes au décès. Chez les personnes qui présentent des symptômes, la fièvre jaune se caractérise généralement par une apparition soudaine des symptômes après une période d'incubation de trois à six jours. Les premiers symptômes comprennent de la fièvre, des frissons, des maux de tête, des maux de dos, des douleurs musculaires, des douleurs
En 2011, I'OMS a publié une révision des recommandations relatives à la vaccination contre la fièvre jaune à la suite de consultations auprès d'experts en médecine des voyages internationaux et d'un examen approfondi des données disponibles $(20 ; 21)$. Voici certaines des modifications apportées :

- Mise à jour des critères de désignation des zones où il existe un risque d'activité du virus amaril. Les zones géographiques ont été classées en quatre catégories en fonction du risque de transmission de la fièvre jaune: (i) zones d'endémie, (ii) zones de transition, (iii) zones à faible potentiel d'exposition et (iv) zones sans risque. Voir l'annexe 1a pour connaître la définition de chacune des catégories.

- Les pays et les zones géographiques où il existe un risque de transmission de la fièvre jaune ont été réévalués à l'aide des nouveaux critères, et des recommandations vaccinales ont été émises en fonction du niveau de risque.

- La vaccination contre la fièvre jaune est recommandée pour les voyageurs se rendant dans des zones d'endémie ou de transition.

- La vaccination contre la fièvre jaune n'est généralement pas recommandée pour les voyageurs dont les itinéraires sont limités à des zones ayant un faible potentiel d'exposition; cependant, on peut l'envisager chez une petite partie de ceux dont les itinéraires pourraient leur faire courir un risque accru d'exposition au virus amaril (par exemple, séjour prolongé, forte exposition aux moustiques, impossibilité d'éviter les piqûres de moustiques).

- La vaccination contre la fièvre jaune n'est pas recommandée chez les voyageurs dont les itinéraires se limitent à des zones considérées comme sans risque.

- Révision des cartes afin d'illustrer les recommandations relatives à la vaccination contre la fièvre jaune et non le risque de fièvre jaune. Les cartes sont fournies à l'annexe $1 \mathrm{c}$ et l'annexe $1 \mathrm{~d}$.

articulaires, des nausées, des vomissements, une photophobie, un léger ictère (jaunisse) et des douleurs épigastriques. Les personnes infectées peuvent présenter un pouls lent et une forte fièvre (signe de Faget). Les symptômes d'ictère empirent au fur et à mesure que la maladie progresse (3;4). On estime que dans $85 \%$ des cas de fièvre jaune, la maladie se résorbe d'elle-même à cette étape (7). Dans les autres cas, après une brève période de 
rémission pouvant durer quelques heures ou une journée, l'état de la personne s'aggrave et la maladie s'attaque au foie, puis finit par causer une insuffisance rénale, des symptômes d'hémorragie et une thrombocytopénie. Le traitement vise les symptômes et consiste en des soins de soutien $(3 ; 4 ; 7)$.

Chez les voyageurs, les caractéristiques cliniques et les antécédents (dates du voyage, lieux visités et activités) aident habituellement à poser le diagnostic initial (7). Chez les voyageurs et les non-voyageurs, on confirme le diagnostic en isolant le virus du sang après inoculation (1). On se sert également d'épreuves immunoenzymatiques

\section{Risque pour les voyageurs}

Le risque pour un voyageur de contracter la fièvre jaune est très difficile à évaluer, car il dépend d'un grand nombre de facteurs tels que la destination, la saison, les activités professionnelles et récréatives, ainsi que l'activité locale du virus $(11 ; 20 ; 21)$.

\section{Destination :}

La destination du voyageur influe de bien des façons sur le risque de contracter la fièvre jaune. La fièvre jaune est la seule maladie transmissible qui fait l'objet d'une surveillance régie par un règlement international (voir la section Mesures de prévention). II prend la forme de Règlement sanitaire international, édicté par l'Organisation mondiale de la Santé et dont la dernière mise à jour remonte à 2005. Certains pays obligent les voyageurs à se faire vacciner contre la fièvre jaune avant d'entrer dans le pays, comme le prévoit le RSI. II est également stipulé dans le RSI que les voyageurs qui ont séjourné ou fait escale dans un pays où la fièvre jaune est endémique doivent présenter un certificat de vaccination contre la maladie. Le vaccin contre la fièvre jaune (ou vaccin antiamaril) n'est pas obligatoire pour entrer dans certains pays où l'on observe des cas de la maladie (p. ex. le Brésil) et, par conséquent, les voyageurs non vaccinés pourraient courir un plus grand risque, plus particulièrement s'ils se rendent dans une région où il existe un risque de contracter la fièvre jaune.

\section{Saison :}

Les moustiques sont généralement plus nombreux pendant ou après la " saison humide » (2). On assiste à une transmission verticale du virus, c'estàdire du moustique femelle à sa descendance (2;5). Le risque pour les voyageurs peut être accru, étant donné qu'un plus grand nombre de vecteurs se trouvent à transmettre la maladie. (méthode ELISA) ou de tests d'amplification par la polymérase (PCR) pour identifier les antigènes ou l'acide nucléique du virus (22;23). Comme il pourrait y avoir des réactions sérologiques croisées avec d'autres flavivirus, cette possibilité devrait être prise en compte au moment du diagnostic (3). De plus, il est parfois difficile d'isoler le virus après la quatrième journée de la maladie (7). Étant donné que la fièvre jaune est considérée comme une maladie à déclaration obligatoire au Canada et à l'échelle internationale en vertu du Règlement sanitaire international (RSI) 2005, tous les diagnostics posés au Canada doivent être déclarés aux autorités de santé publique (19).

\section{Activités professionnelles et récréatives :}

Les activités qui obligent les voyageurs à rester à l'extérieur durant les périodes où les moustiques piquent le plus peuvent accroître le risque de transmission de la fièvre jaune (24).

\section{Activité locale du virus de la fièvre jaune :}

L'activité du virus de la fièvre jaune fluctue. Étant donné que de nombreux pays où la fièvre jaune est présente possèdent une infrastructure de surveillance déficiente, et en raison des difficultés inhérentes à la surveillance étroite des hôtes non humains, l'activité locale du virus est particulièrement difficile à mesurer $(11 ; 17 ; 18)$. Au cours des dernières années, des éclosions sporadiques ont été observées en Afrique et en Amérique du Sud $(6 ; 9 ; 10 ; 25 ; 26)$.

Les voyageurs et les praticiens de la médecine des voyages devraient tenir compte de tous ces risques au moment de la consultation précédant le voyage afin de déterminer si la vaccination contre la fièvre jaune est nécessaire. Comme c'est souvent le cas en médecine des voyages, il faut disposer de données épidémiologiques à jour pour prendre des décisions éclairées.

Il est important d'étudier soigneusement les risques lorsque l'on traite avec des populations chez lesquelles la vaccination est plus susceptible de causer des effets secondaires (voir la section Vaccin et populations spéciales). Les professionnels qui rencontrent ces personnes doivent être au fait de leur itinéraire de voyage et des activités menées dans la région à risque, et disposer de données à jour sur l'épidémiologie de la fièvre jaune. Ces renseignements servent à évaluer les risques et les avantages de la vaccination et à déterminer, au cas par cas, si elle est nécessaire. 


\section{Mesures de prévention}

\section{Règlement sanitaire international et mesures de prévention de la fièvre jaune}

La fièvre jaune est une maladie unique du fait qu'un règlement sanitaire international prévoit I'obligation d'avoir un certificat de vaccination pour se rendre dans certains pays, ou encore pour entrer dans certains pays après avoir séjourné dans une région où la fièvre jaune est endémique (19). Comme l'indique le document Voyages internationaux et santé (27) de l'OMS, la vaccination contre la fièvre jaune vise deux objectifs principaux :

- Éviter la propagation internationale de la maladie en protégeant les pays contre le risque d'importation ou de propagation du virus de la fièvre jaune. Dans ce cas, les pays concernés exigent la vaccination.

- Protéger les voyageurs qui risquent d'être exposés à I'infection amarile (autre appellation de la fièvre jaune).

Ainsi, il se peut qu'un voyageur se présente chez un professionnel de la santé et lui remette une demande de vaccination contre la fièvre jaune provenant d'une agence de voyage ou d'un fournisseur de voyages organisés sans que la raison de la demande de vaccination y soit précisée. Une évaluation adéquate du risque doit alors être faite en fonction de l'itinéraire exact du voyageur (voir la section Risque pour les voyageurs) afin de déterminer s'il est nécessaire d'administrer le vaccin au voyageur pour assurer sa protection ou pour répondre aux exigences relatives à l'entrée dans le pays de destination.

Les mesures de prévention mondiales ont été très efficaces pour éliminer le risque de fièvre jaune qui existait dans de nombreuses régions. Cependant, bon nombre de régions (p. ex. l'Asie du Sud) abritent les deux vecteurs de la maladie, c'est-à-dire les moustiques et les primates non humains, nécessaires à une éventuelle éclosion de fièvre jaune. C'est pour cette raison que plusieurs pays exigent un certificat de vaccination contre la fièvre jaune pour l'entrée sur leur territoire, malgré le fait qu'aucun cas de la maladie n'y ait été déclaré (voir l'annexe 1) (7). Ces exigences sont habituellement destinées aux voyageurs qui viennent de régions où il existe des risques de transmission de la fièvre jaune ou bien qui sont passés par ces régions. Dans une mise à jour faite récemment, l'Organisation mondiale de la Santé (27) déclare qu'un voyageur qui est en transit dans un aéroport international pendant moins de 12 heures ne risquerait pas de contracter la fièvre jaune. Par conséquent, si le seul trajet au sein d'une zone de transmission de la fièvre jaune est un transit, les pays de destinations ultérieurs ne devraient pas le considérer comme étant une exposition réelle. Ces recommandations ont été publiées par l'Organisation mondiale de la Santé, mais chaque gouvernement a le droit de déterminer ses exigences pour entrer dans le pays. Les voyageurs doivent bien s'informer avant le départ.

\section{Vaccination contre la fièvre jaune au Canada}

Les vaccins contre la fièvre jaune administrés au Canada ne sont offerts que dans les centres de vaccination contre la fièvre jaune désignés. Au Canada, l'Agence de la santé publique du Canada est actuellement chargée de désigner les centres de vaccination contre la fièvre jaune (28), dont la liste est accessible à l'adresse www.phac-aspc.gc.ca/ tmp-pmv/travel/clinic-fra.php. Il existe tout de même une exception : les centres de vaccination contre la fièvre jaune des Forces canadiennes désignés par la Direction de protection de la santé des Forces. Ces centres administrent le vaccin contre la fièvre jaune et délivrent le Certificat international de vaccination ou de prophylaxie (voir I'annexe 2a) approuvé que le voyageur apportera en voyage. Le certificat de vaccination est valide pendant dix ans à compter du dixième jour après la date de vaccination ou à compter de la date de rappel. Le rappel devrait être envisagé tous les dix ans; toutefois, certaines données indiquent que la séroconversion assure une protection plus longue, qui pourrait même durer toute la vie (29).

Quant aux personnes qui ne peuvent pas être vaccinées, elles peuvent se procurer un document d'exemption, qui indique la raison médicale pour laquelle la personne ne peut recevoir le vaccin. Cette information peut être fournie utilisant lıen-tête du centre de santé ou sur un Certificat de contre-indication médicale à la vaccination (voir Annexe 2b), que l'Agence émet aux centres de vaccination contre la fièvre jaune.

\section{Le vaccin contre la fièvre jaune}

Le vaccin contre la fièvre jaune est un vaccin vivant atténué, cultivé sur des embryons de poulet auxquels on a administré la souche 17D du virus de la fièvre jaune. À l'échelle mondiale, on utilise les souches 17D-204, 17-213 et 17DD du virus (1). Au Canada, un seul vaccin contre la fièvre jaune a été approuvé : il s'agit d'un vaccin fabriqué à partir de la souche 17D-204 du virus, commercialisé sous 
le nom YF-VAX' ${ }^{M D}$ et produit par la société Sanofi Pasteur Limited (30). Le vaccin YF-VAX ${ }^{\text {MD }}$ est lyophilisé et renferme du sorbitol et de la gélatine qui servent de stabilisants. Aucun agent de conservation n'est ajouté au vaccin ou à son diluant (30).

Selon Sanofi Pasteur, le vaccin doit être conservé à une température située entre deux et huit degrés Celsius (2 à $8^{\circ} \mathrm{C}$ ) (30). Il faut donc surveiller étroitement la réfrigération du vaccin pour s'assurer de maintenir sa viabilité. II faut veiller à ce que ni le vaccin ni le diluant ne gèlent (30). Le vaccin reconstitué doit être gardé au réfrigérateur et utilisé dans l'heure qui suit la reconstitution. Toute portion de vaccin reconstitué non utilisée au bout d'une heure doit être éliminée (30).

Le vaccin contre la fièvre jaune peut être administré en même temps que les vaccins contre les maladies suivantes : rougeole, polio (vaccin oral contre la polio), diphtérie, tétanos, coqueluche, hépatite $B$, hépatite $A$, choléra (vaccin oral contre le choléra) et typhoïde (vaccin oral ou parentéral). Si plusieurs vaccins sont administrés en même temps, il faut utiliser des seringues différentes pour chaque vaccin ainsi que des sites d'injection différents. Si les vaccins ne sont pas administrés simultanément, les vaccins vivants devraient être administrés au moins quatre semaines avant ou après le vaccin contre la fièvre jaune. Cette recommandation est basée sur l'hypothèse selon laquelle les interférons produits en réponse au premier vaccin pourraient avoir un effet inhibiteur temporaire sur les autres vaccins à virus vivant (1).

\section{Risque associé à la vaccination}

Bien que rares, un certain nombre de cas de réaction grave à la vaccination contre la fièvre jaune ont été recensés au cours des dernières années (31-35). Ces cas ont donné lieu à un examen des diverses préparations de vaccin ainsi que de leur utilisation et de leurs indications $(1 ; 30 ; 35)$. Comme dans le cas de tout traitement, la vaccination peut provoquer des effets secondaires graves ou bénins chez un certain pourcentage de la population qui reçoit le vaccin. Tout traitement est conçu pour être utilisé seulement si ses bienfaits l'emportent sur les dangers potentiels.

\section{EFFETS SECONDAIRES BÉNINS DU VACCIN}

Les vaccins contre la fièvre jaune sont généralement bien tolérés. Les réactions au vaccin sont habituellement bénignes et temporaires, et peuvent comprendre des maux de tête, des douleurs musculaires et de la faible fièvre $(1 ; 7 ; 30 ; 36)$. Les rapports sur l'innocuité et l'efficacité du vaccin sont publiés dans le Guide canadien d'immunisation, la monographie du YF-VAXMD, ainsi que Centers for Disease Control and Prevention (CDC) et l'Organisation mondiale de la Santé (OMS). Tous les rapports indiquent que le vaccin est efficace et sans risque. Les réactions apparaissent généralement quelques jours après la vaccination; elles durent entre cinq et dix jours après la date d'administration $(1 ; 7)$. Il existe un grand écart (entre 2 et $30 \%$ ) quant à la fréquence des effets secondaires bénins qui ont été reportés ( $p$. ex. céphalées, myalgie, fièvre légère). Moins d'un pour cent des personnes ayant reçu le vaccin ont dû limiter leurs activités quotidiennes en raison d'un effet secondaire qui sıest produit après la vaccination (30;37).

\section{EFFETS SECONDAIRES GRAVES}

Bien qu'ils soient rares, divers effets secondaires graves liés au vaccin contre la fièvre jaune ont été signalés, notamment les effets suivants:

- Réactions d'hypersensibilité : Le vaccin contre la fièvre jaune peut provoquer des réactions d'hypersensibilité immédiate (éruption cutanée, urticaire, asthme, anaphylaxie). Aux États-Unis, le Vaccine Adverse Event Reporting System (VAERS) indique que, pour 100000 vaccins distribués, des effets secondaires ont été signalés chez 43 personnes après l'administration du vaccin contre la fièvre jaune. Ces effets sont cependant rares : le $\mathrm{GCl}$ fait état d'un taux allant de 1 cas pour 250000 à 1 cas pour 300000 (37). Les réactions d'hypersensibilité se produisent généralement chez les personnes qui ont une sensibilité aux protéines d'œuf et/ou au poulet $(4 ; 11 ; 37 ; 39 ; 40)$. On a découvert que le stabilisant à base de gélatine utilisé dans la fabrication du vaccin était également à l'origine de réactions $(1 ; 11 ; 39)$. Par conséquent, le vaccin ne devrait pas être administré aux personnes souffrant d'allergie aux œufs, au poulet ou à la gélatine. La vaccination peut également entraîner une anaphylaxie chez des personnes n'ayant pas d'allergie connue aux composantes du vaccin. Les personnes chez qui une sensibilité est soupçonnée et devant se faire vacciner devraient être adressées à un allergologue, qui déterminera si la vaccination contre la fièvre jaune doit être envisagée (30).

- Syndrome neurotropique associé au vaccin contre la fièvre jaune (SNA-VFJ) : Le SNA-VFJ était auparavant un syndrome caractérisé par l'apparition de fièvre et d'une encéphalite chez les jeunes enfants. Or, l'incidence de ces effets secondaires a grandement diminué depuis que le vaccin contre la fièvre jaune n'est plus administré aux enfants de moins de six mois (36). Le SNA-VFJ est à présent décrit comme un ensemble de syndromes cliniques: méningo-encéphalite, maladie auto-immune du système nerveux central et/ou maladie auto-immune 
du système nerveux périphérique (syndrome de GuillainBarré), pouvant apparaître chez des personnes de tous les groupes d'âge entre 4 et 23 jours après la vaccination $(1 ; 7)$. Le $\mathrm{GCl}$ ne fournit pas de statistiques sur les cas de SNA-VFJ chez les Canadiens ayant reçu le vaccin contre la fièvre jaune. L'OMS, quant à elle, fait état de 26 cas avérés ou probables de SNA-VFJ depuis 1945, dont deux décès (1). Les CDC rapportent 0,8 cas pour 100000 doses de vaccin contre la fièvre jaune administrées (7). Des études suggèrent que l'âge avancé est un facteur de risque d'effets secondaires graves, y compris le SNAVFJ, du vaccin contre la fièvre jaune (41).

- Syndrome viscérotropique associé au vaccin contre la fièvre jaune (SVA-VFJ) : Ce syndrome est caractérisé par une atteinte grave et une défaillance polyviscérale semblables à celles observées dans les cas de fièvre jaune $(36 ; 42 ; 43)$. Selon le GCl, le risque de SVA-VFJ augmente avec l'âge : chez les personnes de 60-69 ans, on estime que le taux est de 1,0-1,1 pour 100 000; chez les personnes âgées de 70 ans ou plus, il s'élèverait à 2,3-3,2 pour 100000 (38;41). L'OMS estime que le taux de décès associé au SVA-VFJ est de 1 pour 10 millions de doses du vaccin (1). Des effets similaires ont été observés avec cinq préparations différentes du vaccin 17D (44-46). Des enquêtes exhaustives sur un certain nombre de cas semblent indiquer que le SVAVFJ est attribuable à divers facteurs inhérents à l'hôte, et non au degré de virulence du virus présent dans le vaccin. Encore une fois, la fréquence de ces réactions graves (et souvent mortelles) est extrêmement faible. Ces réactions sont associées à des caractéristiques de l'hôte, notamment l'âge avancé ( $\geq 60$ ans) $(34 ; 41)$ et une maladie du thymus où la réaction anormale du système immunitaire ( $p$. ex. thymome et myasthénie grave) (47), et sont observées lors de la série vaccinale primaire. Le SVA-VFJ tend à se développer deux à cinq jours après la vaccination. II n'existe pas de traitement spécifique du SVA-VFJ, à I'exception des soins de soutien qui sont habituellement offerts dans une unité de soins intensifs $(11 ; 38 ; 42 ; 47)$.

Malgré l'information nouvellement publiée sur SNA-VFJ et SVA-VFJ, le vaccin contre la fièvre jaune est très efficace et sûr. Lors de sa réunion de juin 2008, le Comité consultatif mondial de la sécurité vaccinale a répété que « les recommandations relatives à I'utilisation du vaccin antiamaril restaient inchangées » (48). Le message important à retenir ici est de veiller à ce que le motif exact de la vaccination soit compris (risque d'exposition / règlement international). II est également crucial de ne pas exposer les patients au risque, très faible mais non négligeable, associé au vaccin contre la fièvre jaune s'il n'existe pas véritablement de risque de contracter la maladie ou si la vaccination n'est pas nécessaire $(7 ; 27 ; 48)$.

\section{Vaccin et populations spéciales}

La prudence est de mise lorsque les patients appartiennent aux groupes spéciaux suivants :

- Enfants : Les enfants de moins de neuf mois ne doivent généralement pas être vaccinés contre la fièvre jaune (30). Selon certaines études préliminaires $(30 ; 49 ; 50)$, bien que l'incidence des effets secondaires chez les enfants de plus de six mois ne semble pas avoir considérablement augmenté en comparaison à celle chez les enfants de plus de neuf mois, le taux de séroconversion ne serait pas optimal. On remarque d'ailleurs encore une légère augmentation des effets secondaires d'ordre neurologique chez certaines populations ayant fait l'objet d'études de petite taille. Les enfants de moins de six mois courent plus de risques de développer le SNA-VFJ $(1 ; 36)$. L'Advisory Committee on Immunization Practices (ACIP) des États-Unis d'Amérique, recommandent que la décision d'administrer le vaccin à un enfant de six à huit mois devant inévitablement séjourner dans une zone d'endémie devrait être basée sur une analyse des risques d'exposition à la fièvre jaune par rapport aux risques d'effets secondaires après la vaccination. Le vaccin est contre-indiqué pour les enfants de moins de six mois (51).

- Voyageurs âgés : La question de l'administration d'une série vaccinale primaire chez les personnes de plus de 60 ans a été abordée précédemment à la section sur les risques d'effets secondaires (SNA-VFJ et SVA-VFJ). Toute décision quant à l'administration du vaccin à des personnes de ce groupe d'âge devrait être basée sur une analyse du risque relatif associé à la vaccination par rapport au risque de contracter la maladie (7;36-38;41). II faut déterminer, avec le plus de précision possible, la prévalence et la transmission de la maladie dans les pays de destination au moment du voyage (consultation des cartes de recommandations concernant la vaccination qui ont été revues par l'Organisation mondiale de la Santé et les Centers for Disease Control and Prevention [CDC]), ainsi que l'itinéraire exact. S'il existe un risque important de transmission de la fièvre jaune, on peut choisir d'administrer le vaccin en tenant compte du fait qu'il y a un risque légèrement plus élevé d'effets indésirables graves. Cette décision est particulièrement importante pour les voyageurs âgés dont l'itinéraire peut les conduire dans des pays où les exigences d'entrées concernant la vaccination contre la fièvre jaune sont strictes, mais où le risque d'exposition réelle à la maladie est faible ou inexistant. Si l'on décide de ne pas administrer le vaccin compte tenu du faible risque, on peut fournir une lettre d'exemption au patient, mais il faudrait insister sur les mesures de protection individuelle pour éviter les piqûres de moustiques (voir la section Mesures de protection individuelle ci-dessous). II faudrait 
également rappeler au voyageur que la nécessité de recevoir le vaccin devra être réévaluée au moment de ses prochains voyages $(34 ; 41 ; 52-54)$.

- Femmes enceintes : Comme les effets de ce vaccin vivant durant la grossesse ne sont pas bien documentés, la vaccination des femmes enceintes devrait si possible être évitée. Si une femme enceinte doit se rendre dans une région où la fièvre jaune est fortement endémique ou dans une zone d'épidémie, le risque de contracter la maladie pourrait surpasser les risques associés à la vaccination pour la mère ou le fœtus $(7 ; 37)$. Des études préliminaires menées dans des pays en développement ont mis en lumière certaines conséquences néfastes de la transmission congénitale de la maladie et un risque d'avortement spontané associé à la vaccination (55-57), mais il s'agit d'études de petite taille. Les résultats de ces études ont été pondérés par les résultats diautres études qui n'ont révélé aucune conséquence négative chez des femmes enceintes qui avaient été vaccinées par inadvertance au début de leur grossesse (58-61). Si la voyageuse se rend dans un pays qui exige un certificat de vaccination conformément au RSI, mais où la fièvre jaune n'est pas endémique, il faudrait lui remettre une lettre d'exemption plutôt que de lui administrer le vaccin (4).

- Femmes qui allaitent : Jusqu'à récemment, il n'existait qu'un risque théorique de transmission du virus vivant dans le lait maternel. Cependant, en raison d'un incident qui s'est produit récemment au Brésil, on dispose maintenant de données confirmées en laboratoire qui montrent que le virus de la fièvre jaune peut être transmis dans le lait maternel (62). De plus, il existe actuellement un cas d'issue défavorable possible chez un nourrisson qui a été allaité par une mère ayant été vaccinée contre la fièvre jaune au Canada (63). Ces deux cas devraient inciter les professionnels de la santé à être plus prudents lorsqu'ils envisagent la vaccination des femmes qui allaitent. Assurément, s'il n'y a aucun risque de contracter la fièvre jaune dans la région de destination, une lettre d'exemption de la vaccination devrait être fournie à la patiente. Si celle-ci se rend dans une région hautement endémique, il faut alors évaluer les risques associés à la vaccination par rapport au risque de contracter la maladie (37;64).

- Personnes immunodéprimées : Les voyageurs atteints d'une maladie qui affaiblit la réponse immunitaire ou ceux qui prennent des immunomodulateurs devraient éviter les vaccins à virus vivant. De plus, leur réponse à I'antigène pourrait ne pas être suffisante pour assurer une protection adéquate. II est contre-indiqué d'administrer le vaccin contre la fièvre jaune aux personnes atteintes de maladies sous-jacentes graves telles que la leucémie, un lymphome, un thymome, une affection maligne généralisée, un déficit en gammaglobulines, une infection par le virus de l'immunodéficience humaine (VIH) symptomatique ou le syndrome d'immunodéficience acquise (sida) (nombre de lymphocytes CD4 < 200 cellules/ml), ou aux personnes qui prennent une grande quantité de médicaments immunosuppresseurs (7;36;65-67). Ces personnes devraient éviter de se rendre dans des régions où la fièvre jaune est endémique. Si le voyage ne peut être évité, il faudrait fournir à ces patients des conseils sur les précautions à prendre contre les piqûres d'insectes (voir la section Mesures de protection individuelle ci-dessous) et sur le risque de transmission de la fièvre jaune dans la région de destination, ainsi qu'une lettre d'exemption en ce qui concerne la vaccination. Certaines données semblent indiquer que le vaccin peut être administré aux personnes atteintes d'une infection à VIH asymptomatique (nombre de lymphocytes CD4 > 200 cellules/ml), ou entre 15 et $24 \%$ de l'ensemble des cellules chez les enfants $<6$ ans), mais que la vaccination devrait avoir lieu bien avant le voyage afin qu'il soit possible de surveiller les effets secondaires potentiels, et qu'il faudrait évaluer l'efficacité de la vaccination en mesurant les titres d'anticorps neutralisants $(65 ; 68-71)$. Bien que le nombre de cas étudiés soit encore restreint, l'administration du vaccin contre la fièvre jaune à des personnes atteintes du $\mathrm{VIH}$ a révélé que ces patients produisent des titres d'anticorps neutralisants moins élevés, que les titres d'anticorps neutralisants produits sont plus souvent insuffisants pour assurer une protection et que ces titres pourraient diminuer plus rapidement après la vaccination. De plus, les recommandations relatives aux doses de rappel pour les voyageurs immunocompétents (c.-à-d. tous les 10 ans) ne sont probablement pas adéquates pour les voyageurs immunodéprimés. Chez ces patients, il faudrait plutôt envisager de procéder au dosage des titres d'anticorps neutralisants ou même à l'administration d'une dose de rappel après une période de deux à cinq ans (72). La vaccination des membres de la famille et des compagnons de voyage des personnes immunodéprimées n'est pas contre-indiquée, étant donné que le virus est transmis par des moustiques et non directement d'une personne à une autre par simple contact. La prise de stérö̈des à faibles doses (c'est-à-dire $<20 \mathrm{mg}$ de prednisone ou d'un médicament équivalent, ou de moins de $2 \mathrm{mg} / \mathrm{kg}$ pour les enfants de moins de $10 \mathrm{~kg}$ ), l'utilisation de stéroïdes topiques ou la prise de stéroïdes à court terme ( $<2$ semaines) ne devraient pas empêcher la vaccination (7). Pour plus d'information, voir la déclaration du CCMTMV intitulée Le voyageur immunodéprimé (73). 
- Maladie du thymus : Un examen des décès attribués à la vaccination (SVA-VFJ) a fait ressortir une association avec des antécédents de maladie du thymus $(7 ; 36)$. Cet examen portait sur un très petit échantillon, mais I'association semble pertinente et pourrait indiquer que les personnes ayant déjà souffert d'un trouble thymique, par exemple un thymome, une thymectomie ou une myasthénie grave (pour ces syndromes ou pour des agents pathogènes inconnus), ne devraient pas recevoir le vaccin contre la fièvre jaune.

\section{Mesures de protection individuelle (MPI)}

Tous les voyageurs devraient être informés des mesures de protection courantes contre les insectes ainsi que des mesures à prendre en voyage, et ce, peu importe leur état vaccinal en ce qui concerne la fièvre jaune. Les moustiques qui transmettent la fièvre jaune peuvent attaquer au cours de la journée. Par conséquent, les voyageurs doivent se protéger contre les piqûres de moustiques en tout temps. Ces mesures permettent également de prévenir l'infection causée par d'autres maladies transmises par des arthropodes. Pour plus d'information, voir la Déclaration relative aux mesures de protection individuelle pour prévenir les piqûres ou morsures d'arthropodes du CCMTMV (24). Le recours exclusif aux MPI comme méthode de prévention ne serait indiqué que dans le cas des personnes à risque de contracter la fièvre jaune mais ne pouvant pas être vaccinées.

\section{Conséquences possibles si les bons documents ne sont pas présentés}

Les voyageurs doivent aussi être avisés que, même s'ils ont un certificat ou une lettre de contre-indication à la vaccination contre la fièvre jaune, les services de santé à la frontière et/ou les services d'immigration pourraient tout de même refuser leur entrée dans le pays ou les placer en quarantaine à leur arrivée dans le pays de destination (19). Il faut également prévenir les voyageurs des éventuels risques qu'ils peuvent courir en se faisant vacciner dans le pays de destination. 


\section{Résumé des recommandations}

\section{TABLEAU 1 : Fermeté et qualité des preuves—tableau récapitulatif (75)}

\begin{tabular}{l|l}
\hline \multicolumn{2}{l}{ Catégories relatives à la fermeté de chaque recommandation } \\
\hline Catégorie & Définition \\
\hline A & Preuves suffisantes pour recommander l'utilisation. \\
\hline B & Preuves acceptables pour recommander l'utilisation. \\
\hline C & Preuves insuffisantes pour recommander ou déconseiller l'utilisation. \\
\hline D & Preuves acceptables pour déconseiller l'utilisation. \\
\hline E & Preuves suffisantes pour déconseiller l'utilisation. \\
\hline Catégories relatives à la qualité des preuves sur lesquelles reposent les recommandations \\
\hline Grade & Definition \\
\hline I & Données obtenues dans le cadre d'au moins un essai comparatif convenablement randomisé. \\
\hline II & $\begin{array}{l}\text { Données obtenues dans le cadre d'au moins un essai clinique bien conçu, sans randomisation, d'études de cohortes } \\
\text { ou d'études analytiques cas-témoins, réalisées de préférence dans plus d'un centre, à partir de plusieurs séries } \\
\text { chronologiques ou résultats spectaculaires d'expériences non comparatives. }\end{array}$ \\
\hline III & $\begin{array}{l}\text { Opinions exprimées par des sommités dans le domaine et reposant sur l'expérience clinique, des études descriptives } \\
\text { ou des rapports de comités d'experts. }\end{array}$ \\
\hline
\end{tabular}

TABLEAU 2 : Recommandations sur l'administration du vaccin contre la fièvre jaune en fonction du groupe

\begin{tabular}{|c|c|c|}
\hline Groupe & Recommandations préalables au voyage & Pertinence \\
\hline $\begin{array}{l}\text { Adultes (moins de } 60 \text { ans) en bonne santé, qui voyagent } \\
\text { dans une région où la fièvre jaune est jugée comme } \\
\text { étant une maladie endémique ou de transition }\end{array}$ & Vaccination recommandée & A II \\
\hline $\begin{array}{l}\text { Adultes (plus de } 60 \text { ans) en bonne santé, qui voyagent } \\
\text { dans une région où la fièvre jaune est jugée comme } \\
\text { étant une maladie endémique ou de transition et qui se } \\
\text { présentent pour une primo-vaccination }\end{array}$ & $\begin{array}{l}\text { Il est recommandé de réaliser une évaluation précise des risques } \\
\text { On peut administrer le vaccin s'il existe des risques élevés de } \\
\text { transmission* }\end{array}$ & DII \\
\hline $\begin{array}{l}\text { Enfants (plus de neuf mois) en bonne santé, qui voyagent } \\
\text { dans une région où la fièvre jaune est jugée comme } \\
\text { étant une maladie endémique ou de transition }\end{array}$ & Vaccination recommandée & A II \\
\hline Enfants de moins de six mois & Vaccination contre-indiquée & E II \\
\hline Enfants entre six et neuf mois & $\begin{array}{l}\text { Il est recommandé de réaliser une évaluation précise des risques } \\
\text { On peut administrer le vaccin s'il existe des risques élevés de } \\
\text { transmission* }\end{array}$ & DII \\
\hline Femmes enceintes & $\begin{array}{l}\text { Il est recommandé de réaliser une évaluation précise des risques } \\
\text { On peut administrer le vaccin s'il existe des risques élevés de } \\
\text { transmission* }\end{array}$ & DII \\
\hline Femmes qui allaitent & $\begin{array}{l}\text { Il est recommandé de réaliser une évaluation précise des risques } \\
\text { On peut administrer le vaccin s'il existe des risques élevés de } \\
\text { transmission* }\end{array}$ & DIII \\
\hline $\begin{array}{l}\text { Personnes atteintes d'une infection par le VIH } \\
\text { asymptomatique dont le nombre de lymphocytes CD4 } \\
\text { s'élève à moins de } 200 \text { cellules } / \mathrm{mm}^{3} \text { (ou représente entre } \\
15 \text { et } 24 \% \text { du nombre total de cellules chez les enfants } \\
\text { de moins de } 6 \text { ans) }\end{array}$ & $\begin{array}{l}\text { Il est recommandé de réaliser une évaluation précise des risques } \\
\text { On peut administrer le vaccin s'il existe des risques élevés de } \\
\text { transmission* }\end{array}$ & $B \|$ \\
\hline
\end{tabular}




\begin{tabular}{l|l|l}
\hline Groupe & Recommandations préalables au voyage & Pertinence \\
\hline $\begin{array}{l}\text { Personnes ayant des antécédents de maladie du } \\
\text { thymus associée à des réactions anormales du système } \\
\text { immunitaire (p. ex. thymome ou myasthénie grave) }\end{array}$ & Vaccination contre-indiquée & E II \\
\hline $\begin{array}{l}\text { Personnes immunodéprimées (lymphome, VIH [nombre } \\
\left.\text { de lymphocytes CD4 inférieur à } 200 \text { cellules } / \mathrm{mm}^{3}\right],\end{array}$ & Vaccination non recommandée \\
$\begin{array}{l}\text { traitements immunosuppresseurs, immunosuppression } \\
\text { primaire, maladies auto-immunes) }\end{array}$ & & E II \\
\hline $\begin{array}{l}\text { Personnes qui développent des réactions allergiques } \\
\text { mortelles aux cufs ou au poulet ou à tout autre } \\
\text { composant du vaccin }\end{array}$ & Vaccination contre-indiquée & E III \\
\hline
\end{tabular}

* La vaccination chez ces groupes présente des risques élevés d'apparition d'effets indésirables (chez le patient ou chez l'enfant); par conséquent, il n'est pas possible de faire des recommandations d'ordre général. L'administration d'un vaccin doit être étudiée au cas par cas. On peut envisager de reporter le voyage. S'il est nécessaire de voyager et si la personne se rend dans une région où la maladie est endémique ou épidémique et où les risques de transmission de la fièvre jaune sont importants, les risques de contracter la maladie pourraient s'avérer plus problématiques que les risques que comporte la vaccination. Veuillez consulter le document pour connaître les discussions détaillées sur la vaccination chez ces groupes.

\section{Annexe 1 : Zones à rique de la fièvre jaune}

\section{ANNEXE 1A : Critères de classification des risques pour la fièvre jaune, 2011 (20;21)}

\begin{tabular}{|c|c|c|c|}
\hline Classification & Description & $\begin{array}{l}\text { Risque } \\
\text { d'infection }\end{array}$ & $\begin{array}{l}\text { Recommandation } \\
\text { quant à la vaccination }\end{array}$ \\
\hline Endémique & $\begin{array}{l}\text { - Régions où la transmission du virus de la fièvre jaune selon un mode } \\
\text { enzootique est constante pendant de longues périodes. } \\
\text { - Présence de vecteurs de la fièvre jaune et d'hôtes primates non humains. } \\
\text { - Cas de fièvre jaune signalés chez les primates humains et non humains. } \\
\text { - Cas de fièvre jaune signalés chez l'homme avant que la région ne soit } \\
\text { couverte. } \\
\text { - Les analyses du sérum révèlent une infection grave. } \\
\text { - Transmission à un niveau stable. }\end{array}$ & Élevé & Recommandée \\
\hline De transition & $\begin{array}{l}\text { - Régions limitrophes à la zone où sévit la maladie endémique; il existe } \\
\text { des preuves d'une transmission périodique au cours de l'expansion } \\
\text { épizootique ou épidémique de la fièvre jaune. } \\
\text { - Présence de vecteurs de la fièvre jaune et d'hôtes primates non humains. } \\
\text { - Il est possible que des cas chez l'homme soient signalés après de } \\
\text { longues périodes. } \\
\text { - Les analyses du sérum révèlent une infection antérieure }\end{array}$ & Modéré à élevé & Recommandée \\
\hline $\begin{array}{l}\text { Faibles risques } \\
\text { d'exposition }\end{array}$ & $\begin{array}{l}\text { - Régions limitrophes aux régions d'endémie ou de transition. } \\
\text { - Présence de vecteurs de la fièvre jaune et d'hôtes primates non humains. } \\
\text { - Aucun cas de fièvre jaune signalés chez les primates humains et non } \\
\text { humains. } \\
\text { - Les analyses du sérum peuvent révéler une infection antérieure, } \\
\text { habituellement faible. }\end{array}$ & Faible & $\begin{array}{l}\text { Habituellement non } \\
\text { recommandée* }\end{array}$ \\
\hline Aucun risque & $\begin{array}{l}\text { - Régions où il n'existe aucun risque de transmission de la fièvre jaune } \\
\text { en raison de l'absence de preuves d'une propagation, par le passé ou } \\
\text { à l'heure actuelle, du virus de la fièvre jaune dans les régions ou bien } \\
\text { en raison des conditions environnementales qui ne sont pas favorables } \\
\text { à la transmission de la fièvre jaune. }\end{array}$ & Non & Non recommandée \\
\hline
\end{tabular}

* La vaccination pourrait être envisagée pour un petit sous-ensemble de voyageurs dont l'itinéraire présenterait des risques élevés d'exposition au virus de la fièvre jaune ( $p$. ex. séjour prolongé, forte exposition aux moustiques, impossibilité d'éviter les piqûres de moustiques). 
ANNEXE 1B : Pays où il y a un risque de transmission de la fièvre jaune, par continent, 2011 (27)

\begin{tabular}{|c|c|c|}
\hline \multicolumn{2}{|l|}{ Afrique } & \multirow{2}{*}{$\begin{array}{l}\text { Amérique centrale et Amérique du Suc } \\
\text { Argentine }^{\dagger}\end{array}$} \\
\hline Angola & Guinée & \\
\hline Bénin & Guinée-Bissau & Bolivie $^{\dagger}$ \\
\hline Burkina Faso & Kenya & Brésil $^{+}$ \\
\hline Burundi & Libéria & Colombie \\
\hline Cameroun & Mali ${ }^{+}$ & Équateur ${ }^{\dagger}$ \\
\hline République centrafricaine & Mauritanie $^{\dagger}$ & Guyane française \\
\hline Tchad $^{+}$ & Niger $^{\dagger}$ & Guyana \\
\hline Congo & Nigéria & Panama $^{\dagger}$ \\
\hline Côte d'Ivoire & Rwanda & Paraguay \\
\hline République démocratique du Congo & Sénégal & Pérou $^{\dagger}$ \\
\hline Guinée équatoriale & Sierra Leone & Suriname \\
\hline Éthiopie & Soudan ${ }^{\dagger}$ & Trinité-et-Tobago $^{\dagger}$ \\
\hline Gabon & Togo & Venezuela $^{\dagger}$ \\
\hline Gambie & Ouganda & \\
\hline Ghana & & \\
\hline
\end{tabular}

* Il se peut que la désignation des régions où il existe un risque de transmission de la fièvre jaune change. Les voyageurs et les fournisseurs de soins de santé doivent consulter les dernières données disponibles sur le site Web de l'Organisation mondiale de la Santé à l'adresse suivante : www.who.int/ith/fr/index.html

+ Les pays indiqués en caractères gras nécessitent des preuves de la vaccination contre la fièvre jaune, et il se peut qu'ils changent. D'autres pays exigent des voyageurs venant d'un pays où la fièvre jaune est endémique des preuves de la vaccination contre la maladie. La liste exhaustive des exigences propres à chaque pays peut être consultée sur le site Web des Centers for Disease Control and Prevention (CDC), à l'adresse wwwnc.cdc.gov/travel, ou sur celui de l'Organisation mondiale de la Santé, à l'adresse www.who.int/ith/fr/index.html

† Le risque de transmission de la fièvre jaune est présent seulement dans une partie du pays. Consultez les cartes de l'OMS en annexes 1c et 1d.

\section{ANNEXE 1C : Recommendations concernant la vaccination antiamarile, Afrique, 2010 (21)}

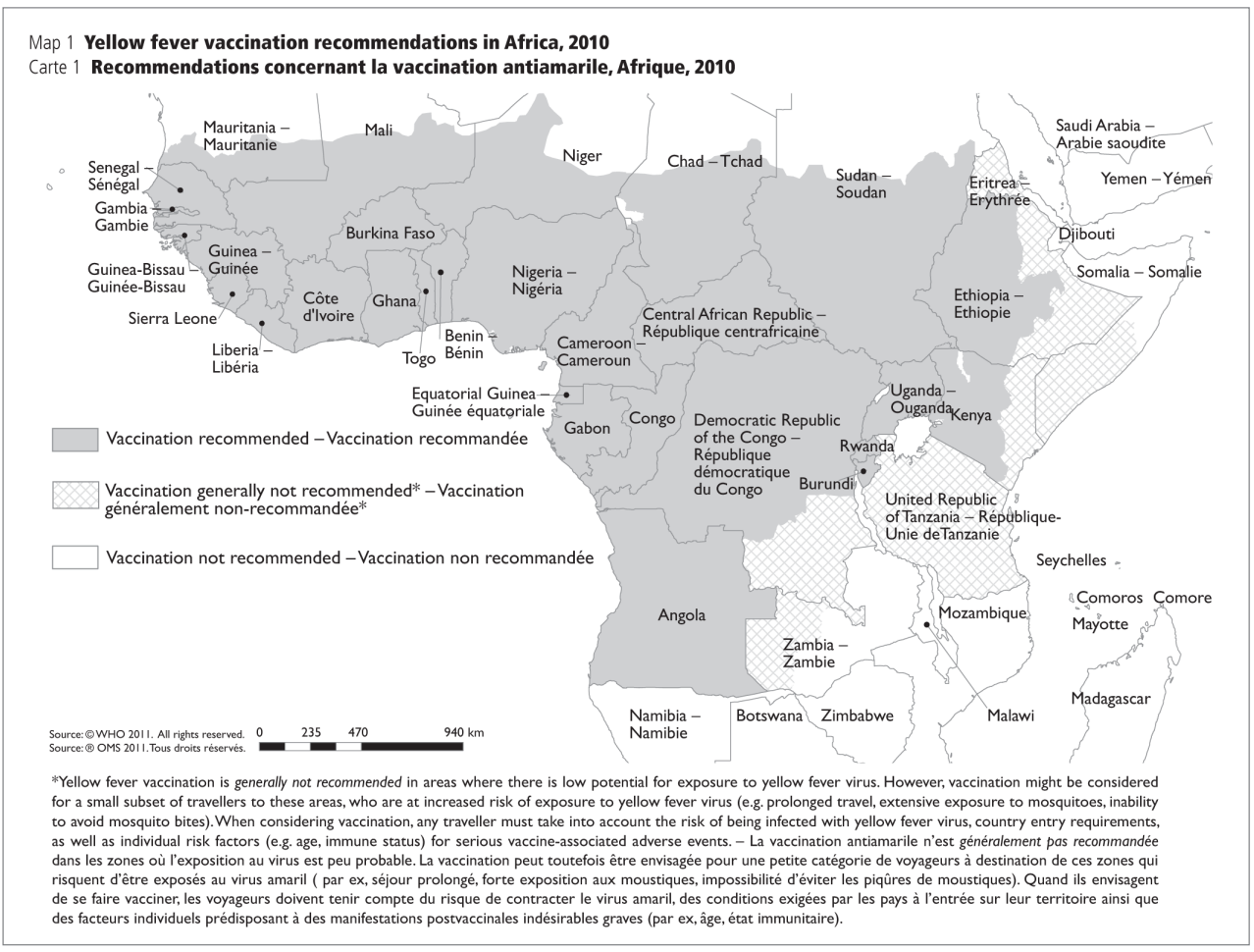


ANNEXE 1D : Recommendations concernant la vaccination antiamarile, Amériques, 2010 (21)

Map 2 Yellow fever vaccination recommendations in the Americas, 2010

Carte 2 Recommendations concernant la vaccination antiamarile, Amériques, 2010

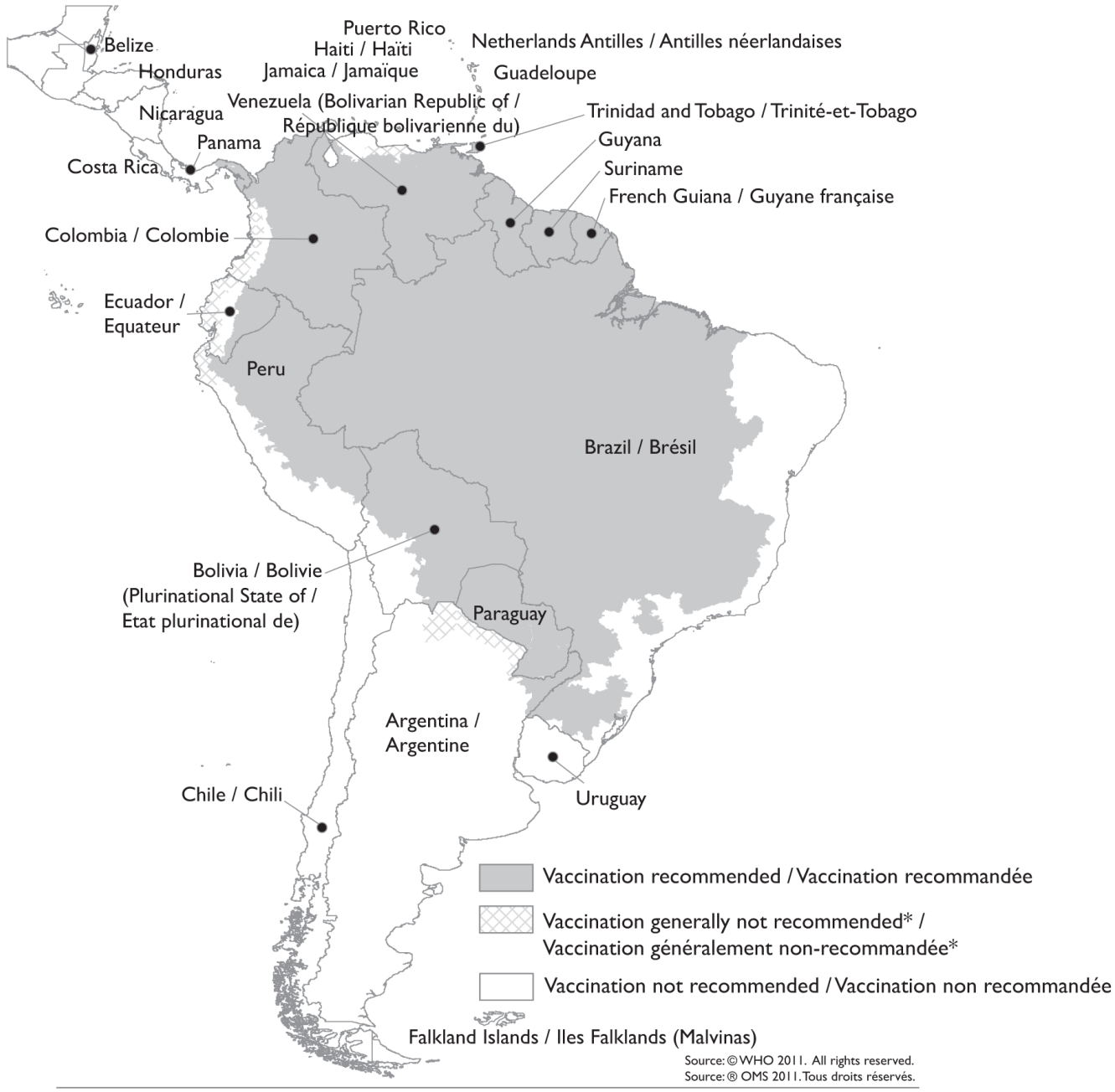

* Yellow fever vaccination is generally not recommended in areas where there is low potential for exposure to yellow fever virus. However, vaccination might be considered for a small subset of travellers to these areas, who are at increased risk of exposure to yellow fever virus (e.g. prolonged travel, extensive exposure to mosquitoes, inability to avoid mosquito bites). When considering vaccination, any traveller must take into account the risk of being infected with yellow fever virus, country entry requirements, as well as individual risk factors (e.g. age, immune status) for serious vaccine-associated adverse events.

* La vaccination antiamarile n'est généralement pas recommandée dans les zones où l'exposition au virus est peu probable. La vaccination peut toutefois être envisagée pour une petite catégorie de voyageurs à destination de ces zones qui risquent d'être exposés au virus amaril ( par ex, séjour prolongé, forte exposition aux moustiques, impossibilité d'éviter les piqûres de moustiques). Quand ils envisagent de se faire vacciner, les voyageurs doivent tenir compte du risque de contracter le virus amaril, des conditions exigées par les pays à l'entrée sur leur territoire ainsi que des facteurs individuels prédisposant à des manifestations postvaccinales indésirables graves (par ex, âge, état immunitaire). 


\section{ANNEXE 2 : Centres de vaccination contre la fièvre jaune au Canada}

En vertu de l'annexe 7 du Règlement sanitaire international (2005), « les États Parties désignent des centres déterminés de vaccination antiamarile sur leur territoire pour garantir la qualité et la sécurité des procédures et des matériels utilisés » (19). En tant que pays signataire de ce règlement, le Canada doit désigner des centres de vaccination contre la fièvre jaune. Au Canada, les centres sont désignés par l'Agence de la santé publique du Canada, avec laquelle on peut communiquer à l'adresse et aux numéros suivants :

Programme de vaccination contre la fièvre jaune Division de la santé voyage et santé liée à la migration Direction générale de la prévention et du contrôle des maladies infectieuses

Agence de la santé publique du Canada 380, chemin Hunt Club, IA 5902A

Ottawa (Ontario) K1A OK9

Courriel : yfinfofj@phac-aspc.gc.ca

Téléphone : 613-957-8739

Télécopieur : 613-952-8286
Pour obtenir la liste des centres de vaccination contre la fièvre jaune au Canada, veuillez consulter le site Web de l'Agence de la santé publique du Canada à l'adresse www.phac-aspc.gc.ca/tmp-pmv/yf-fj/index-fra.php. 


\section{ANNEXE 2A : Exemple de Certificat international de vaccination ou de prophylaxie délivré par l'Agence de la} santé publique du Canada

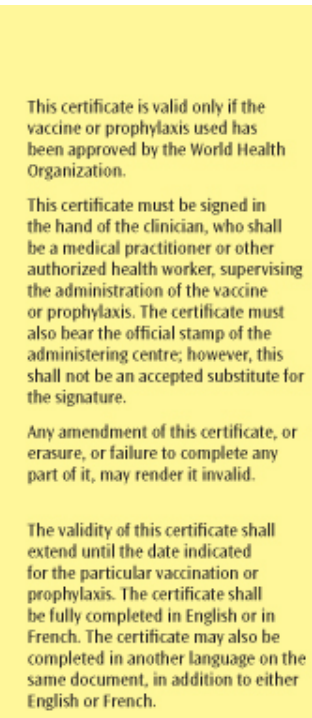

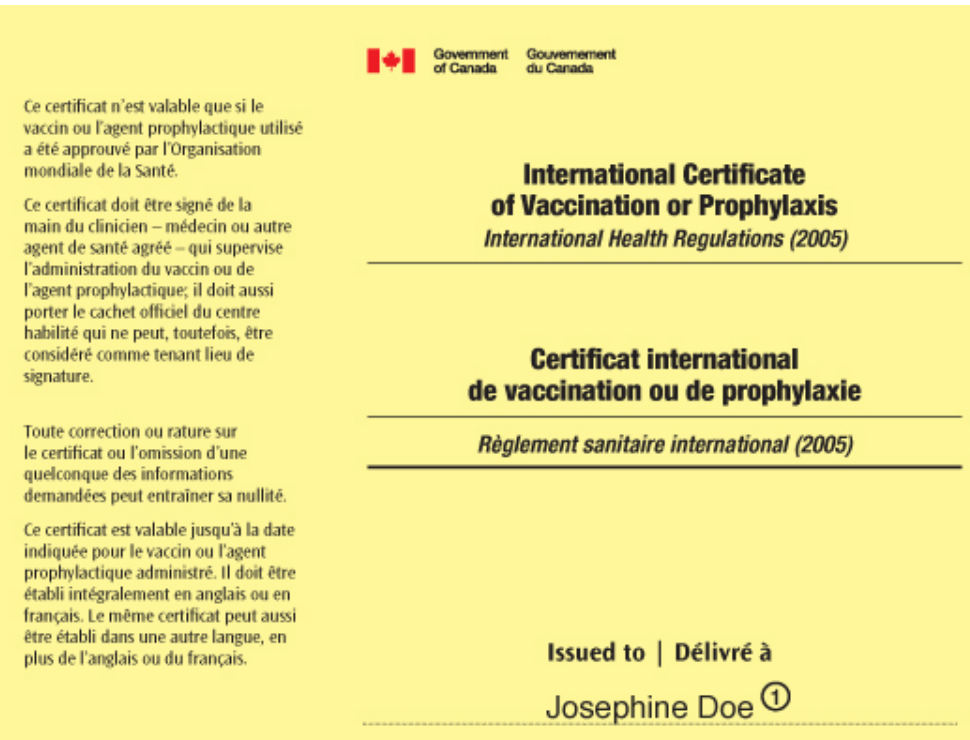

Canadä

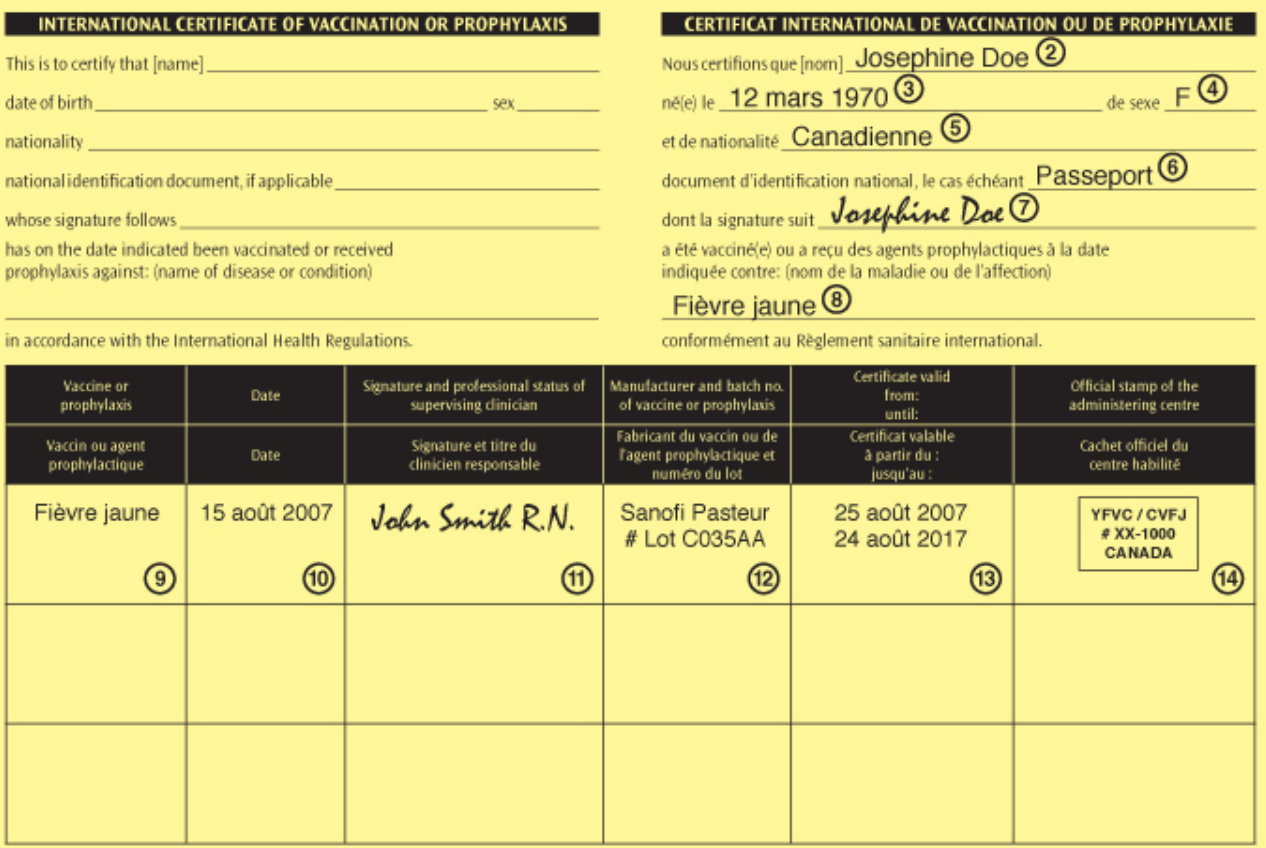

Bien qu'il n'existe actuellement pas de lignes directrices acceptées à l'échelle internationale sur la nécessité de remplir ce certificat, l'Agence de la santé publique du Canada recommande aux centres de vaccination contre la fièvre jaune de le remplir. Pour connaître toutes les recommandations, veuillez consulter les « Procédures pour les Centres de vaccination contre la fièvre jaune au Canada » (28). 
ANNEXE 2B : Exemple de Certificat de contre-indication médicale à la vaccination délivré par l'Agence de la santé publique du Canada

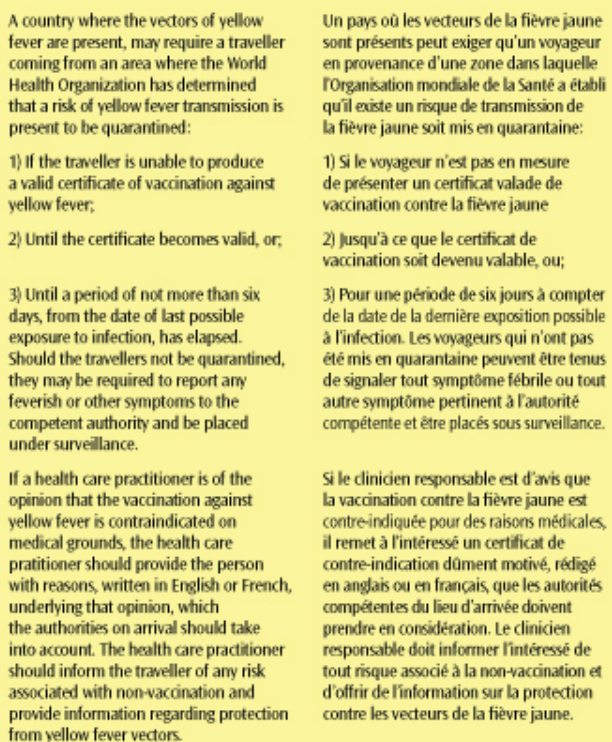

1) If the traveller is unable to produce a valid certificate of vaccination agains yellow fever;

2) Until the certificate becomes valid, or,

3) Until a period of not more than six days, from the date of last possible Should the travellers not be quarantined, they may be required to report any feverish or other symptoms to the competent authority and be placed under surveillance.

If a health care practitioner is of the opinion that the vaccination agains yellow fever is contraindicated on medical grounds, the health care pratitioner should provide the person with reasons, written in English or underlying that opinion, which into account. The health care praditioner tho accumt the health care pracilion should inform the traveller of any risk provide information regarding protection provide information regar
from yellow fever vectors

1) Si le voyageur n'est pas en mesure de presenter un certificat valade de vaccination contre la fièvre jaune

2) Jusquà ce que le certificat de vacination soit devenu valable, ou;

3) Pour une période de six jours à compter de la date de la demière exposition possible à linfection. Les vovageurs qui n'ont pas êté mis en quarantaine peuvent être tenus de signaler tout symptôme fébrile ou tout autre symptōme pertinent a Fautorité compétente et être placés sous surveillance

Si le dinicien responsable est d awis que la vaccination contre la fièvre jaune est contreindiqueet pour des rasons médicalcs il remet à lintéressé un certificat de contre-indication dûment motivé, rédige en angas on en francais que les autorit competentes da lieu d arrivee donvent prendre en consideration. Le dinicien responsable doit informer finteresse de toffri de lissoce a la nonvaccination contre les vecteurs de la fièvire jaune.

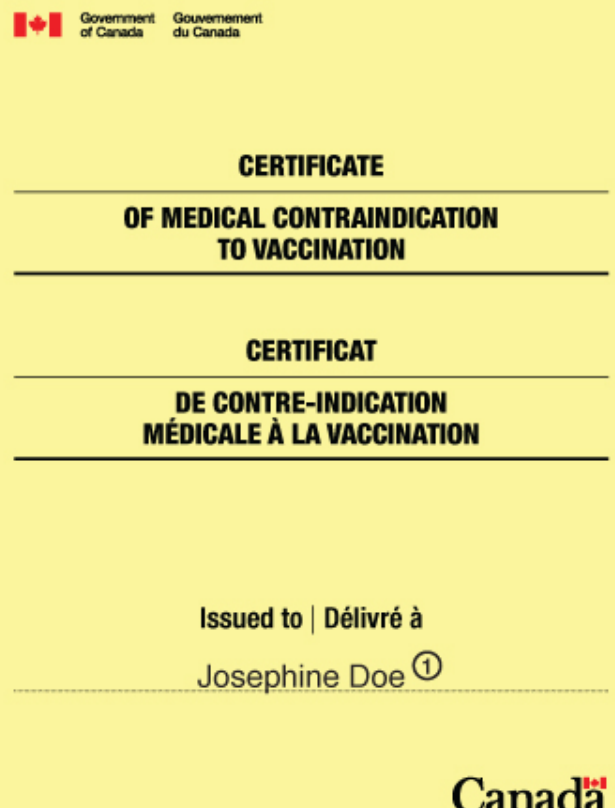

Canadä

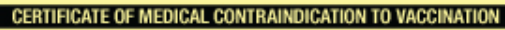

This is to certify that Iname date of birth nationality

nationalidentification document, if applicable

whose signature follows

cannot be vaccinated against iname of disease or conditioni

because of the following reason:

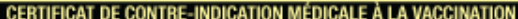

Nouscertifionsque [nom] Josephine Doe (2) nèंe) le 12 mars 1970 (3) de sexe F (4) et de nationalité Canadienne (5) document d'identification national, le cas échéant Passeport (6) dont la signature suit Josephine $\mathrm{DaC}_{\text {(7) }}$

ne peut être vacciné(e) contre (nom de la maladie ou de l'affection) Fièvre jaune (8) pour la raison suivante

Allergie sévère aux œufs (9)

\begin{tabular}{|c|c|c|c|c|}
\hline Contraindicated vactine & Date & $\begin{array}{l}\text { Signature and protesional status } \\
\text { of supervising clinician }\end{array}$ & $\begin{array}{l}\text { Medical contraindication } \\
\text { valid from: } \\
\text { until: }\end{array}$ & $\begin{array}{l}\text { Official stamp of the } \\
\text { administering centre }\end{array}$ \\
\hline Vatcin contre indiqué & Date & $\begin{array}{l}\text { Signature et titre du } \\
\text { dinicien responsable }\end{array}$ & $\begin{array}{l}\text { Contre indication mediciale } \\
\text { â partir du : } \\
\text { jusquau: }\end{array}$ & $\begin{array}{l}\text { Cachet of ficiel du } \\
\text { centre habilité }\end{array}$ \\
\hline Fièvre jaune & 15 août 2007 & John Smith R.N. & $\begin{array}{c}25 \text { août } 2007 \\
30 \text { novembre } 2007\end{array}$ & $\begin{array}{c}\text { YFVC/CVFJ } \\
\text { XX-1000 } \\
\text { CANADA }\end{array}$ \\
\hline
\end{tabular}

Afin d'aider les fournisseurs de soins de santé, l'Agence de la santé publique du Canada met à la disposition des centres de vaccination contre la fièvre jaune des Certificats de contre-indication médicale à la vaccination qui permettent d'attester par écrit la contre-indication à l'administration du vaccin contre la fièvre jaune. Veuillez consulter les «Procédures pour les Centres de vaccination contre la fièvre jaune au Canada » afin de connaître toutes les recommandations pour remplir ce document (28). 


\section{Références}

(1) World Health Organization. Yellow fever vaccine. WHO position paper. Weekly epidemiological record 2003;78(40):349-59.

(2) Monath TP. Yellow fever: An update. Lancet Infect Dis 2001;1(1):11-20.

(3) Heymann DL. Control of Communicable Diseases Manual 19th edition. Washington: American Public Health Association (APHA); 2008.

(4) World Health Organization. Fact Sheet: Yellow Fever. Geneva: WHO [le site Web]. Disponible à : www.who.int/mediacentre/factsheets/fs100/fr/ index.html; 2011.

(5) Staples JE, Monath TP. Yellow fever: 100 Years of discovery. Journal of the American Medical Association 2008;300(8):960-2.

(6) World Health Organization. Yellow fever in the WHO African and American Regions, 2010. Weekly epidemiological record 2011;86(34):365-76.

(7) Centers for Disease Control and Prevention. CDC Health Information for International Travel 2012: The Yellow Book. Atlanta: U.S. Department of Health and Human Services, Public Health Service; 2011.

(8) World Health Organization. Progress in the control of yellow fever in Africa. Weekly epidemiological record 2005;80(6):50-5.

(9) World Health Organization. Yellow fever in Africa and Central and South America, 2008-2009. Weekly epidemiological record 2011;86(4):25-36.

(10) World Health Organization. Global Alert and Response: Yellow Fever. Geneva: WHO [le site Web]. Disponible à : www.who.int/csr/disease/ yellowfev/en; 2011.

(11) Barnett ED. Yellow fever: Epidemiology and prevention. Clin Infect Dis 2007;44(6):850-6.

(12) McFarland JM, Baddour LM, Nelson JE, Elkins SK, Craven RB, Cropp BC, et al. Imported yellow fever in a United States citizen. Clin Infect Dis 1997;25(5):1143-7.

(13) Hall P, Fojtasek M, Pettigrove J, Perdue J, Hendricks K, Stanley S, et al. Fatal Yellow Fever in a traveler returning from Amazonas, Brazil, 2002. J Am Med Assoc 2002;287(19):2499-500.
(14) Centers for Disease Control and Prevention. Fatal yellow fever in a traveler returning from Venezuela, 1999. MMWR CDC Surveill Summ 2000;49(14):303-5.

(15) Bae HG, Drosten C, Emmerich P, Colebunders R, Hantson P, Pest $\mathrm{S}$, et al. Analysis of two imported cases of yellow fever infection from Ivory Coast and the Gambia to Germany and Belgium. J Clin Virol 2005;33(4):274-80.

(16) Public Health Agency of Canada. National Notifiable Diseases On-Line. Ottawa: PHAC [le site Web]. Disponible à : http://dsol-smed.hc-sc.gc.ca/ dsol-smed/ndis/list-fra.php; 2005.

(17) Ellis BR, Barrett ADT. The enigma of yellow fever in East Africa. Rev Med Virol 2008;18(5):331-46.

(18) Behrens RH. Yellow fever recommendations for tourists to Kenya: A flawed risk assessment? J Travel Med 2008;15(5):285-6.

(19) World Health Organization. International Health Regulations (2005). 2 ed. Geneva: WHO; 2008.

(20) Jentes ES, Poumerol G, Gershman MD, Hill DR, Lemarchand J, Lewis RF, et al. The revised global yellow fever risk map and recommendations for vaccination, 2010: consensus of the Informal WHO Working Group on Geographic Risk for Yellow Fever. Lancet Infect Dis 2011 Aug;11(8):622-32.

(21) World Health Organization. Revised recommendations for the yellow fever vaccination for international travellers, 2011. Weekly epidemiological record 2011;86(37):401-16.

(22) Bae HG, Nitsche A, Teichmann A, Biel SS, Niedrig M. Detection of yellow fever virus: A comparison of quantitative real-time PCR and plaque assay. J Virol Methods 2003;110(2):185-91.

(23) Vazquez S, Valdes O, Pupo M, Delgado I, Alvarez M, Pelegrino J, et al. MAC-ELISA and ELISA inhibition methods for detection of antibodies after yellow fever vaccination. J Virol Methods 2003;110(2):179-84.

(24) Committee to Advise on Tropical Medicine and Travel. Statement on Personal Protective Measures to Prevent Arthropod Bites - Update. Can Commun 2012 Nov;38(ACS-3):1-18.

(25) Mutebi JP, Barrett ADT. The epidemiology of yellow fever in Africa. Microbes Infect 2002;4(14):1459-68. 
(26) Reiter P, Cordellier R, Ouma JO, Cropp CB, Savage $H M$, Sanders EJ, et al. First recorded outbreak of yellow fever in Kenya, 1992-1993. II. Entomologic investigations. Am J Trop Med Hyg 1998;59(4):650-6.

(27) World Health Organization. International Travel and Health: Situation as on 1 January 2011. Geneva: WHO; 2011.

(28) Public Health Agency of Canada. Procedures for Yellow Fever Vaccination Centres in Canada. Ottawa: Her Majesty the Queen in Right of Canada; 2011.

(29) Poland JD, Calisher CH, Monath TP, Downs WG, Murphy K. Persistence of Neutralizing Anitbody 30-35 Years After Immunization with 17D Yellow Fever Vaccine. Bulletin of the World Health Organization 1981;59(6):895-900.

(30) Sanofi Pasteur. Product Monograph YF-VAX® Yellow Fever Vaccine. Toronto: Sanofi-Pasteur Ltd; 2009.

(31) Choudri Y, Walop W. Review of adverse events reported following use of yellow fever vaccineCanada, 1987-2000. Can Commun Dis Rep 2002;28(2):9-15.

(32) World Health Organization. Adverse events following yellow fever vaccination. Weekly epidemiological record 2001;76(29):217-8.

(33) Levy S, Mullane K, Miller M, Siva S, Barnes D, Dhaliwal $P$, et al. Adverse events associated with 17D-derived yellow fever vaccination - United States, 2001-2002. MMWR CDC Surveill Summ 2002;51(44).

(34) Lawrence GL, Burgess MA, Kass RB. Age-related risk of adverse events following yellow fever vaccination in Australia. Commun Dis Intell 2004;28(2):244-8.

(35) Lawrence G, Menzies R, Burgess M, McIntyre P, Wood N, Boyd I, et al. Surveillance of adverse events following immunisation: Australia, 2000-2002. Commun Dis Intell 2003;27(3):307-23.

(36) Barrett ADT, Monath TP, Barban V, Niedrig M, Teuwen DE. 17D yellow fever vaccines: New insights. A report of a workshop held during the World Congress on Medicine and Health in the Tropics, Marseille, France, Monday 12 September 2005. Vaccine 2007;25(15):2758-65.
(37) Public Health Agency of Canada. Canadian Immunization Guide Evergreen Edition; Part 4: Active Vaccines, Yellow Fever Vaccine. Ottawa: PHAC [le site Web]. Disponible à : www.phac-aspc.gc.ca/publicat/ cig-gci/p04-yfev-fiej-fra.php; 2012.

(38) Lindsey NP, Schroeder BA, Miller ER, Braun MM, Hinckley AF, Marano N, et al. Adverse event reports following yellow fever vaccination. Vaccine 2008;26(48):6077-82.

(39) Kelso JM, Mootrey GT, Tsai TF. Anaphylaxis from yellow fever vaccine. J Allergy Clin Immunol 1999;103(4):698-701.

(40) Tounian P, Delacourt C, De Blic J, Paupe J, Scheinmann P. Administration of egg-containing vaccines to egg-allergic children. Arch Fr Pediatr 1993;50(3):191-5.

(41) Khromava AY, Eidex RB, Weld LH, Kohl KS, Bradshaw $\mathrm{RD}$, Chen RT, et al. Yellow fever vaccine: An updated assessment of advanced age as a risk factor for serious adverse events. Vaccine 2005;23(25):3256-63.

(42) Hayes EB. Acute viscerotropic disease following vaccination against yellow fever. Trans R Soc Trop Med Hyg 2007;101(10):967-71.

(43) Munoz J, Vilella A, Domingo C, Nicolas JM, De Ory F, Corachan M, et al. Yellow fever-associated viscerotropic disease in Barcelona, Spain. J Travel Med 2008;15(3):202-5.

(44) Kitchener S. Viscerotropic and neurotropic disease following vaccination with the 17D yellow fever vaccine, ARILVAX. Vaccine 2004;22(17-18):2103-5.

(45) Martin M, Tsai TF, Cropp B, Chang GJJ, Holmes DA, Tseng J, et al. Fever and multisystem organ failure associated with 17D-204 yellow fever vaccination: A report of four cases. Lancet 2001;358(9276):98-104.

(46) Belsher JL, Gay P, Brinton M, DellaValla J, Ridenour R, Lanciotti $R$, et al. Fatal multiorgan failure due to yellow fever vaccine-associated viscerotropic disease. Vaccine 2007;25(50):8480-5.

(47) Centers for Disease Control and Prevention. Fever, jaundice, and multiple organ system failure associated with 17D-derived yellow fever vaccination, 1996-2001. MMWR CDC Recomm Rep 2001;50(30): 643-5. 
(48) World Health Organization. Meeting of Global Advisory Committee on Vaccine Safety, 18-19 June 2008. Weekly epidemiological record 2008 Aug 8;83(32):287-92.

(49) Osinusi K, Akinkugbe FM, Akinwolere OA, Fabiyi A. Safety and efficacy of yellow fever vaccine in children less thanone-year-old. West Afr J Med 1990;9(3):200-3.

(50) Sood SK. Immunization for children traveling abroad. Pediatr Clin North Am 2000;47(2):435-48.

(51) Advisory Committee on Immunization Practices. Yellow Fever Vaccine - Recommendations of the Advisory Committee on Immunization Practices. MMWR Morb Mortal Wkly Rep 2010;59(7):1-27.

(52) Leder K, Weller PF, Wilson ME. Travel vaccines and elderly persons: Review of vaccines available in the United States. Clin Infect Dis 2001;33(9):1553-66.

(53) Monath TP, Cetron MS, McCarthy K, Nichols R, Archambault WT, Weld L, et al. Yellow fever 17D vaccine safety and immunogenicity in the elderly. Hum Vaccin 2005;1(5):207-14.

(54) Martin M, Weld LH, Tsai TF, Mootrey GT, Chen RT, Niu M, et al. Advanced age a risk factor for illness temporally associated with yellow fever vaccination. Emerg Infect Dis 2001;7(6):945-51.

(55) Nishioka SDA, Nunes-Araùjo FRF, Pires WP, Silva FA, Costa HL. Yellow fever vaccination during pregnancy and spontaneous abortion: A case-control study. Trop Med Int Health 1998;3(1):29-33.

(56) Robert E, Vial T, Schaefer C, Arnon J, Reuvers M. Exposure to yellow fever vaccine in early pregnancy. Vaccine 1999;17(3):283-5.

(57) Tsai TF, Paul R, Lynberg MC, Letson GW. Congenital yellow fever virus infection after immunization in pregnancy. J Infect Dis 1993;168(6):1520-3.

(58) Nasidi A, Monath TP, Vandenberg J, Tomori O, Calisher $\mathrm{CH}$, Hurtgen $\mathrm{X}$, et al. Yellow fever vaccination and pregnancy: A four-year prospective study. Trans R Soc Trop Med Hyg 1993;87(3):337-9.

(59) Suzano CES, Amaral E, Sato HK, Papaiordanou PM, Marba S, Pessoto $M$, et al. The effects of yellow fever immunization (17DD) inadvertently used in early pregnancy during a mass campaign in Brazil. Vaccine 2006;24(9):1421-6.
(60) Cavalcanti DP, Salom+úo MA, Lopez-Camelo J, Pessoto MA, Sato H, Amaral EM, et al. Early exposure to yellow fever vaccine during pregnancy. Trop Med Int Health 2007;12(7):833-7.

(61) D'Acremont V, Tremblay S, Genton B. Impact of vaccines given during pregnancy on the offspring of women consulting a travel clinic: A longitudinal study. J Travel Med 2008;15(2):77-81.

(62) Centers for Disease Control and Prevention. Transmission of Yellow Fever Vaccine Virus Through Breast-Feeding - Brazil, 2009. MMWR Morb Mortal Wkly Rep 2010;59(5):130-2.

(63) Kuhn S, Twele-Montecinos L, MacDonald J, Webster P, Law B. Case report: probable transmission of vaccine strain of yellow fever virus to an infant via breast milk. CMAJ 2011 Mar 8;183(4):E243-E245.

(64) Cetron MS, Marfin AA, Julian KG, Gubler DJ, Sharp DJ, Barwick RS, et al. Yellow fever vaccine. Recommendations of the Advisory Committee on Immunization Practices (ACIP), 2002. MMWR Recomm Rep 2002;51(RR-17):1-11.

(65) Bruyand $\mathrm{M}$, Receveur MC, Pistone $\mathrm{T}$, Verdière $\mathrm{CH}$, Thiebaut R, Malvy D. Yellow fever vaccination in non-immunocompetent patients. Med Mal Infect 2008;38(10):524-32.

(66) Cohn J, Blumberg EA. Immunizations for renal transplant candidates and recipients. Nat Clin Pract Nephrol 2009;5(1):46-53.

(67) Sester M, Gärtner BC, Girndt M, Sester U. Vaccination of the solid organ transplant recipient. Transpl Rev 2008;22(4):274-84

(68) Receveur MC, Thiébaut R, Vedy S, Malvy D, Mercié $P$, Bras ML. Yellow fever vaccination of human immunodeficiency virus-infected patients: report of 2 cases. Clinical infectious diseases : an official publication of the Infectious Diseases Society of America 2000;31(3):E7-E8.

(69) Gowda R, Cartwright K, Bremner JAG, Green ST. Yellow fever vaccine: A successful vaccination of an immunocompromised patient. Eur J Haematol 2004;72(4):299-301. 
(70) Tattevin P, Depatureaux AG, Chapplain JM, Dupont M, Souala F, Arvieux C, et al. Yellow fever vaccine is safe and effective in HIV-infected patients. AIDS 2004;18(5):825-7.

(71) Pistone T, Verdiere CH, Receveur MC, Ezzedine K, Lafon ME, Malvy D. Immunogenicity and tolerability of yellow fever vaccination in 23 French HIV-infected patients. Curr HIV Res 2010 Sep 1;8(6):461-6.

(72) Veit O, Niedrig M, Chapuis-Taillard C, Cavassini M, Mossdorf E, Schmid P. Immunogenicity and safety of yellow fever vaccination for $102 \mathrm{HIV}$-infected patients. Clin Infect Dis 2009;48(5):659-66.

(73) Committee to Advise on Tropical Medicine and Travel. The immunocompromised traveller. Can Comm Dis Rep 2007;33(ACS-4):1-24.

(74) Barwick R. History of thymoma and yellow fever vaccination. Lancet 2004;364(9438):936.

(75) Committee to Advise on Tropical Medicine and Travel. Evidence-based medicine. Can Comm Dis Rep 1994;20(17):145-7. 